\title{
Surgically induced astigmatism after phacoemulsification by temporal clear corneal and superior clear corneal approach: a comparison
}

This article was published in the following Dove Press journal:

Clinical Ophthalmology

\section{Archana Sunil Nikose \\ Dhrubojyoti Saha \\ Pradnya Mukesh Laddha \\ Mayuri Patil}

Department of Ophthalmology, N.K.P. Salve Institute and LMH, Nagpur, Maharashtra, India
Correspondence: Archana Sunil Nikose Department of Ophthalmology, N.K.P. Salve Institute and LMH, 103 Vijay Arcade, 16 Shivaji Nagar, Nagpur 44000I, Maharashtra, India Tel +9l 9422875865

Email archananikose@gmail.com
Introduction: Cataract surgery has undergone various advances since it was evolved from ancient couching to the modern phacoemulsification cataract surgery. Surgically induced astigmatism (SIA) remains one of the most common complications. The introduction of sutureless clear corneal incision has gained increasing popularity worldwide because it offers several advantages over the traditional sutured limbal incision and scleral tunnel. A clear corneal incision has the benefit of being bloodless and having an easy approach, but SIA is still a concern.

Purpose: In this study, we evaluated the SIA in clear corneal incisions with temporal approach and superior approach phacoemulsification. Comparisons between the two incisions were done using keratometric readings of preoperative and postoperative refractive status.

Methodology: It was a hospital-based prospective interventional comparative randomized control trial of 261 patients conducted in a rural-based tertiary care center from September 2012 to August 2014. The visual acuity and detailed anterior segment and posterior segment examinations were done and the cataract was graded according to Lens Opacification Classification System II. Patients were divided for phacoemulsification into two groups, group A and group B, who underwent temporal and superior clear corneal approach, respectively. The patients were followed up on day $1,7,30$, and 90 postoperatively. The parameters recorded were uncorrected visual acuity, best-corrected visual acuity, slit lamp examination, and keratometry. The mean difference of SIA between 30th and 90th day was statistically evaluated using paired $t$-test, and all the analyses were performed using SPSS 18.0 (SPSS Inc.) software.

Results: The mean postoperative SIA in group A was 0.998 D on the 30th day, which reduced to $0.768 \mathrm{D}$ after 90 days, and in group B the SIA after 30 days was $1.651 \mathrm{D}$, whereas it reduced to $1.293 \mathrm{D}$ after 90 days.

Conclusion: Temporal clear corneal incision is evidently better than superior clear corneal incision as far as SIA is concerned.

Keywords: phacoemulsification, temporal, clear corneal, SIA

\section{Introduction}

Cataract surgery has undergone various advances since it was evolved. It started from ancient couching then transformed to intracapsular cataract surgery and finally evolved to the modern phacoemulsification cataract surgery. The primary aim is a good postoperative visual rehabilitation without correction with immediate mobilization, but the main obstacle is surgically induced astigmatism (SIA). Over time, various surgeons have strived hard and invented different incisions to reduce the SIA. The outcome of a cataract surgery depends on various factors like incision, approach, type of surgery, mode of intraocular lens (IOL) insertion, and type of IOL. ${ }^{1}$ 
The introduction of self-sealing clear corneal incision has gained popularity worldwide as it offers several benefits over the traditional sutured limbal incisions and scleral tunnel. ${ }^{2}$

Clear corneal incision has advantages of increased safety, decreased inflammation and pain, as well as reduced SIA. ${ }^{1}$ Clear corneal wounds have revolutionized cataract surgeries by reducing the surgical time and leading to faster postoperative recovery as compared to the scleral tunnel approach.

Postoperative SIA depends on location, size, and architecture of the wound, and also the surgeons position and comfort during the procedure. ${ }^{3}$ The small size incision gives a rapid and a stable optical recovery, and thus a lesser SIA. ${ }^{4}$ Many studies were done to compare the astigmatism with different types of small incisions in different locations like superior, superonasal, superotemporal, and temporal. Regarding the architecture of the cornea, giving phacoemulsification incision on the steepest corneal axis at the time of cataract surgery can correct a small amount of astigmatism. Other options like peripheral corneal relaxing incisions and toric IOLs were also safe and effective for treating more than 1 diopter of preexisting astigmatism. ${ }^{1,5}$

In our study, we compared the SIA in clear corneal phacoemulsification by temporal approach, with superior approach. Comparisons between SIA of the two incisions were done using keratometric reading of preoperative and postoperative refractive changes.

\section{Materials and methods Background}

A hospital-based prospective interventional comparative randomized control trial of 261 eyes of patients was conducted in a rural-based tertiary care center from September 2012 to August 2014. The study protocol, patient information sheet, and consent form were approved by the Institutional ethics committee of NKP Salve Institute of Medical Sciences and Lata Mangeshkar Hospital (Ethics committee registration No ECR/88/Inst/MH/2013/RR-16) and followed the tenets of the Declaration of Helsinki. All patients were selected from the outpatient department randomly and were divided into group A and group B. Group A included 138 cases who underwent phacoemulsification through temporal clear corneal approach, and group B had 123 cases who underwent the procedure through superior clear corneal approach.

All the patients provided written informed consent to participate in the study. Those above the age of 40 years who understood the study and were willing were enrolled. Patients with posterior subcapsular cataract, cortical cataract, or posterior polar cataract were included, and grading was done according to Lens Opacification Classification System II.

Patients with astigmatism of more than three diopters (D) in both meridians, complicated cataract, corneal diseases, pseudoexfoliation, primary or secondary glaucoma, macular or retinal diseases, and diabetic retinopathy were excluded from the study. Also, those not willing to participate in the study and lost to follow-up were excluded subsequently.

\section{Workup}

All patients underwent slit-lamp examination and posterior segment examination, and uncorrected and best-corrected visual acuity (UCVA and BCVA) were recorded. All UCVA, BCVA were converted to logarithm of the minimum angle of resolution (LogMAR). The keratometric readings in diopteric power were taken using a Potec refractometer and the IOL power was calculated with NIDEK A scan machine using SRK II formula. After routine preoperative investigations and preanesthetic assessment, the patients were randomly allotted by a computer generated sheet to either group A or group B.

\section{Surgical procedures}

All phacoemulsification surgeries were done by a single right-handed surgeon (AN) under peribulbar anesthesia. The machine used for phacoemulsification was AMO Sovereign compact, and acrylic hydrophilic foldable IOLs were implanted.

In temporal approach, the surgeon sits at the 9 o'clock position in the case of the right eye and at 3 o'clock position for the left eye. A side port was made at $90^{\circ}$ to the planned main port ie, at 12 o'clock in the right eyes and 6 o'clock in the left eyes. Anterior capsular staining was done with Trypan blue, which was then washed out with balanced salt solution (BSS) after approximately 20 seconds, and anterior chamber (AC) formation was done with hydroxy propyl methyl cellulose (2\%). A main port was made with a clear corneal biplanar self-sealing horizontal incision with $2.8 \mathrm{~mm}$ keratome about $0.5 \mathrm{~mm}$ inside the limbus. The keratome goes parallel to the corneal surface for one-third of the corneal thickness, then dips toward the anterior chamber. This change in direction of the keratome gives a biplanar incision. In the superior approach, the main port was made at the 12 o'clock position and the side port was made at the 3 o'clock position for both the eyes. The technique for nuclear fragmentation used was direct chop, and the rest of the surgical steps for both the approaches were done as for routine phacoemulsification.

Patients were started on topical antibiotic and steroid combination and were followed up on the 1st, 7 th, 30th and 
90th postoperative day. The parameters which were recorded on all days were UCVA, BCVA, and slit-lamp and fundus examination, and autorefractometry and keratometry were done after 1 week follow-up.

\section{Statistical analysis}

SIA was calculated by subtracting the preoperative astigmatism and postoperative astigmatism by a simple subtraction method without taking the axis into consideration. The association of type of cataract and treatment groups was determined using $\chi^{2}$ test. The statistical significance of difference in the proportion of each LogMAR score in the two treatment groups was studied using $z$-test. The difference in the mean K-vertical and K-horizontal parameters between the two groups was tested for significance using $t$-test for independent samples. The mean difference of SIA between the 30th and 90th day was statistically evaluated using paired $t$-test. The statistical significance was evaluated at 5\% level, and all the analyses were performed using SPSS 18.0 (SPSS Inc., Chicago, IL, USA) software.

\section{Results}

The mean age of the patients of group A was $61.63 \pm 8.35$ $\mathrm{SD}$ years and in group B was $62.28 \pm 8.26 \mathrm{SD}$ years. In group A, there were 71 (51.4\%) males and 67 (48.6\%) females, whereas in group B the males numbered 68 (55.3\%) and females 55 (44.7\%).

The mean preoperative LogMAR score was 0.9 in both group A and group B. However, the difference in the two means was statistically insignificant with $p$-value of 0.557 $(p>0.05)$ as obtained using paired $t$-test (Figure 1).
After 7 days in group A, the mean LogMAR visual acuity score (UCVA) was 0.36; while in group B, the mean LogMAR score was 0.47 . The difference in the two means was statistically significant with a $p$-value of $0.002(p<0.05)$ as obtained using $t$-test. Similarly, after day 90 the mean LogMAR score (BCVA) was 0.03 in group A; while in group B, the mean LogMAR score was 0.08. The difference in the two means was statistically significant with a $p$-value of $<0.0001$ $(p<0.05)$ as obtained using $t$-test (Figure 2).

Table 1 provides the distribution of patients according to SIA and study groups. In group A, the mean astigmatism on the 30th day was 0.988 , and on the 90th day it reduced to 0.768 , and the difference in the two means was statistically significant with a $p$-value $<0.0001$ as obtained using paired $t$-test. Similarly in group B, the mean astigmatism on the 30th day was 1.651 , while on the 90th day it was 1.293, and here also the difference in the two means was statistically significant (Table 1).

\section{Discussion}

The goal of modern cataract surgery is to minimize postoperative corneal astigmatism for best visual outcome. This requires an exact evaluation of corneal curvature before and after surgery as the incisions may induce a variable amount of corneal astigmatism.

The mean preoperative LogMAR score did not differ significantly in the two groups $(p=0.557)$. Individual LogMAR scores were $0.48(p=0.589), 0.60(p=0.075), 1.00$ $(p=0.220)$, and $1.30(p=0.874)$ in both groups. Thus, essentially there was equitable distribution of patients with regards to LogMAR scores. Higher values of LogMAR score usually relate to poor visual acuity. ${ }^{6}$

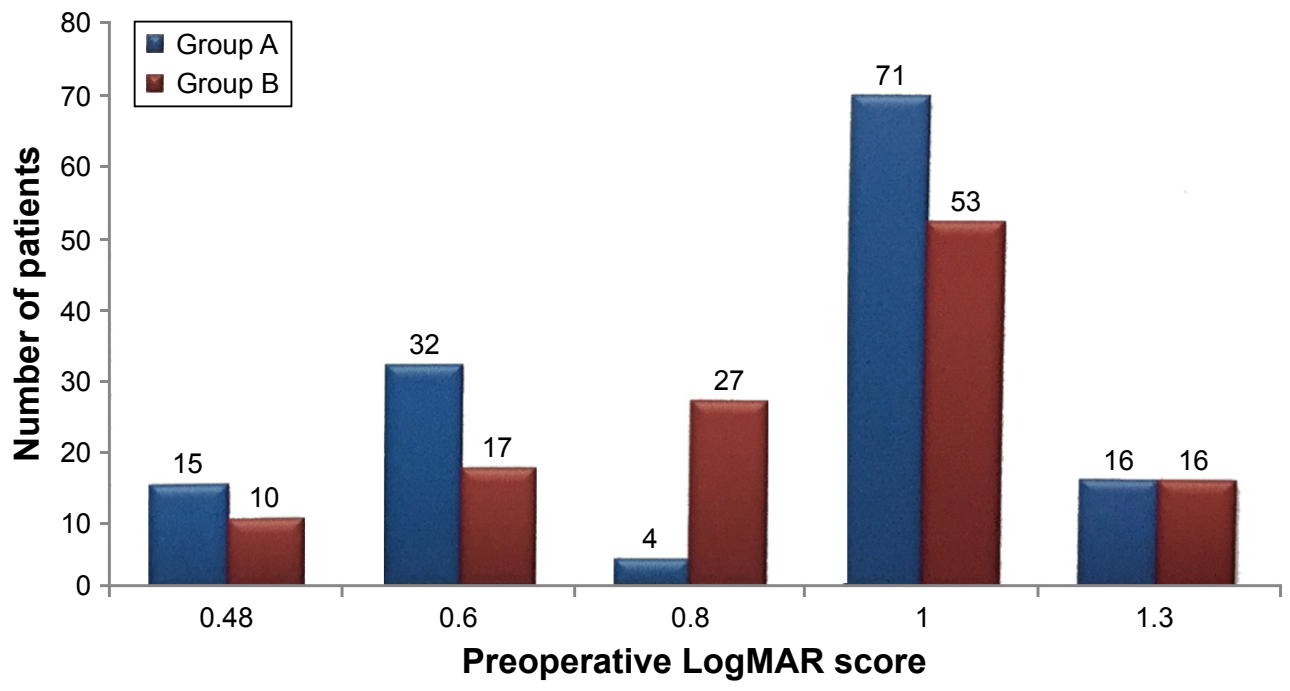

Figure I Preoperative LogMAR score of both groups. Group A, temporal approach; Group B - supereior approach. Abbreviation: LogMAR, logarithm of the minimum angle of resolution. 


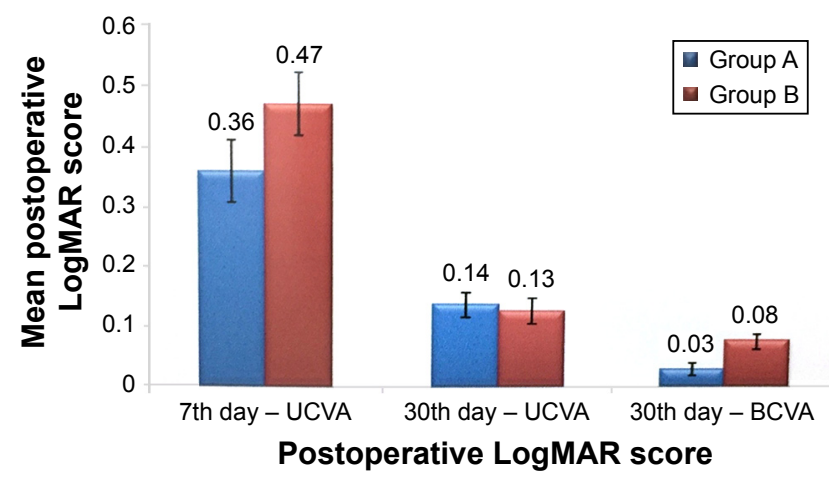

Figure 2 Postoperative LogMAR score of both groups. Group A, temporal approach; Group B - supereior approach.

Abbreviations: BCVA, best-corrected visual acuity; LogMAR, logarithm of the minimum angle of resolution; UCVA, uncorrected visual acuity.

Je et $\mathrm{al}^{7}$ did a prospective study of 60 eyes and divided patients into two groups: temporal clear corneal and nasal clear corneal. They recorded UCVA and BCVA in both groups at 1 and 3 months after surgery. The mean UCVA at 3 months found in group A was $0.25 \pm 0.30$ and in group B was $0.17 \pm 0.15$, which is comparable to our study ( $p$-value 0.338). Similarly in our study, after 3 months UCVA was $0.14 \pm 0.12$ for group $\mathrm{A}$ and $0.13 \pm 0.12$ for group $\mathrm{B}(p=0.527$ ). The BCVA at day 90 was significantly better in group $\mathrm{A}$ than group B $(0.03 \pm 0.06$ versus $0.08 \pm 0.09, p<0.0001)$.

Preoperative astigmatism was absent in $18.12 \%(25 / 138)$ of patients in group A and $23.58 \%$ (29/123) of patients in group B. A maximum number of patients in both groups had astigmatism in the range of 1-2 D. The type of astigmatism also did not differ in the two groups significantly ( $p=0.550$ ). In group A, with the rule (WTR) was $37.7 \%$ and against the rule (ATR) was $44.2 \%$ and nil was $18.1 \%$, whereas in Group B WTR was $35.7 \%$, ATR was $40.7 \%$, and no astigmatism was noted in $23.6 \%$ of subjects (Table 2). Similar observations were made by Pakravan et al $^{3}$ who compared the astigmatic outcomes of temporal versus nasal clear corneal incisions in phacoemulsification cataract surgery. They found preoperative WTR in $30.00 \%$, ATR in $50 \%$, and no astigmatism in $20 \%$ in the temporal group, whereas WTR was $40 \%$, ATR was $25 \%$, and no astigmatism was $35 \%$ in the nasal group.

In our study, the average postoperative astigmatism in group A was around $1 \mathrm{D}$, whereas in group B average astigmatism was around $1.5 \mathrm{D}$. The mean SIA in group A was $0.98 \mathrm{D}$ on the 30th day, which reduced to $0.768 \mathrm{D}$ after 90 days. In group B, the mean SIA was $1.651 \mathrm{D}$ after 30 days, whereas it reduced to $1.293 \mathrm{D}$ after 90 days. These observations proved that the SIA reduces after 90 days and that there is a significant difference between 30th and 90th day SIA (Figure 3).

Likewise Je et $\mathrm{al}^{7}$ performed phacoemulsification through $3 \mathrm{~mm}$ temporal and nasal clear corneal incision with $6 \mathrm{~mm}$ foldable IOL. They stated that temporal incision induced less SIA as compared to nasal incision. They found that the mean SIA in the temporal group after 1 month was $0.81 \pm 0.64$ $\mathrm{D}$, whereas in the nasal group it was $0.92 \pm 0.53 \mathrm{D}$. The SIA reduced after 3 months to $0.53 \pm 0.39 \mathrm{D}$ in the temporal group, whereas it was $0.62 \pm 0.48 \mathrm{D}$ in the nasal group.

Table I Distribution of patients according to astigmatism and study groups

\begin{tabular}{|c|c|c|c|c|c|c|}
\hline \multirow{3}{*}{$\begin{array}{l}\text { Astigmatism } \\
\text { (D) }\end{array}$} & \multirow{2}{*}{\multicolumn{2}{|c|}{ Preoperative number (\%) }} & \multicolumn{4}{|c|}{ Postoperative number (\%) } \\
\hline & & & \multicolumn{2}{|l|}{ 30th day } & \multicolumn{2}{|l|}{ 90th day } \\
\hline & $\begin{array}{l}\text { Group A } \\
(n=138)\end{array}$ & $\begin{array}{l}\text { Group B } \\
(n=\mid 23)\end{array}$ & $\begin{array}{l}\text { Group A } \\
(n=134)\end{array}$ & $\begin{array}{l}\text { Group B } \\
(n=122)\end{array}$ & $\begin{array}{l}\text { Group A } \\
(n=134)\end{array}$ & $\begin{array}{l}\text { Group B } \\
(n=122)\end{array}$ \\
\hline 0 & $25(18.12)$ & $29(23.58)$ & II (8.2I) & $3(2.46)$ & $21(15.67)$ & $10(8.2)$ \\
\hline 0.25 & $2(1.45)$ & $\mathrm{I}(0.8 \mathrm{I})$ & $19(14.18)$ & $3(2.46)$ & $26(19.4)$ & $6(4.92)$ \\
\hline 0.5 & $8(5.8)$ & $14(11.38)$ & $13(9.7)$ & $3(2.46)$ & $18(13.43)$ & II (9.02) \\
\hline 0.75 & $8(5.8)$ & $4(3.25)$ & II (8.2I) & $4(3.28)$ & $12(8.96)$ & $9(7.38)$ \\
\hline I & $21(15.22)$ & $27(21.95)$ & $33(24.63)$ & $13(10.66)$ & $26(19.4)$ & $14(\mid \mathrm{I} .48)$ \\
\hline 1.25 & $12(8.7)$ & $6(4.88)$ & $5(3.73)$ & $7(5.74)$ & $5(3.73)$ & $7(5.74)$ \\
\hline 1.5 & $14(10.14)$ & $12(9.76)$ & $19(14.18)$ & $24(19.67)$ & $10(7.46)$ & $2 I(I 7.2 I)$ \\
\hline 1.75 & $15(10.87)$ & $4(3.25)$ & $5(3.73)$ & $9(7.38)$ & $5(3.73)$ & $8(6.56)$ \\
\hline 2 & $16(11.59)$ & $12(9.76)$ & $17(12.69)$ & $36(29.5 I)$ & $10(7.46)$ & $3 I(25.4 I)$ \\
\hline 2.25 & $5(3.62)$ & $2(1.63)$ & $0(0)$ & $2(1.64)$ & I (0.75) & $2(1.64)$ \\
\hline 2.5 & $5(3.62)$ & $6(4.88)$ & I $(0.75)$ & $13(10.66)$ & $0(0)$ & $2(1.64)$ \\
\hline 2.75 & $4(2.9)$ & $2(1.63)$ & $0(0)$ & $4(3.28)$ & $0(0)$ & $0(0)$ \\
\hline \multirow[t]{3}{*}{3} & $3(2.17)$ & $4(3.25)$ & $0(0)$ & I (0.82) & $0(0)$ & I (0.82) \\
\hline & & Mean & $0.988^{*}$ & $1.65 \mathrm{I} * *$ & $0.768^{*}$ & $1.293 * *$ \\
\hline & & SD & 0.629 & 0.642 & 0.622 & 0.695 \\
\hline
\end{tabular}

Notes: ${ }^{*} p<0.000$ I (HS); ${ }^{* *} p<0.000$ I (HS) using paired $t$-test.

Abbreviations: HS, highly significant; SD, standard deviation. 
Table 2 Distribution of astigmatism in patients according to type and study groups

\begin{tabular}{|c|c|c|c|c|}
\hline \multirow{3}{*}{$\begin{array}{l}\text { Type of } \\
\text { astigmatism }\end{array}$} & \multirow{2}{*}{\multicolumn{2}{|c|}{$\frac{\text { Preoperative }}{\text { Number (\%) }}$}} & \multirow{2}{*}{\multicolumn{2}{|c|}{$\begin{array}{l}\text { Postoperative } \\
\text { Number (\%) } \\
\end{array}$}} \\
\hline & & & & \\
\hline & $\begin{array}{l}\text { Group A } \\
(n=138)\end{array}$ & $\begin{array}{l}\text { Group B } \\
(n=123)\end{array}$ & $\begin{array}{l}\text { Group A } \\
(n=134)\end{array}$ & $\begin{array}{l}\text { Group B } \\
(n=122)\end{array}$ \\
\hline ATR & $61(44.2)$ & $50(40.7)$ & $43(32.1)$ & $113(92.6)$ \\
\hline WTR & $52(37.7)$ & 44 (35.7) & $62(61.2)$ & $4(3.3)$ \\
\hline No astigmatism & $25(18.1)$ & $29(23.6)$ & $9(6.7)$ & $5(4.1)$ \\
\hline
\end{tabular}

Abbreviations: ATR, against the rule; WTR, with the rule.

Similarly, Moon et a $1^{4}$ studied the efficiency and stability of astigmatism by incision size. They studied three groups of $2.5,3$, and $3.5 \mathrm{~mm}$ self-sealing corneal incisions. The mean SIA in $2.5 \mathrm{~mm}$ group was $1.05 \mathrm{D}$, in $3.0 \mathrm{~mm}$ group it was $0.84 \mathrm{D}$, whereas in $3.5 \mathrm{~mm}$ group it was $0.95 \mathrm{D}$. Finally they concluded that the $3.0 \mathrm{~mm}$ incision size had the least SIA, ${ }^{4}$ similar to our study in which we found SIA of $0.76 \mathrm{D}$ in the temporal group and 1.29 in the superior group with the incision size of $2.8 \mathrm{~mm}$.

Also, Giansanti et al ${ }^{8}$ prospectively studied 146 eyes of 146 patients and compared $2.75 \mathrm{~mm}$ temporal clear corneal incisions with superior approach. They concluded that temporal corneal incision had lower SIA as compared to superior clear corneal incision.

In a similar prospective randomized study, Borasio et $\mathrm{al}^{9}$ assessed SIA after phacoemulsification in eyes with mild to moderate corneal astigmatism by temporal versus on-axis clear corneal incisions. The SIA after 2 months was $0.34 \mathrm{D}$ in the temporal group, whereas it was $0.63 \mathrm{D}$ in the

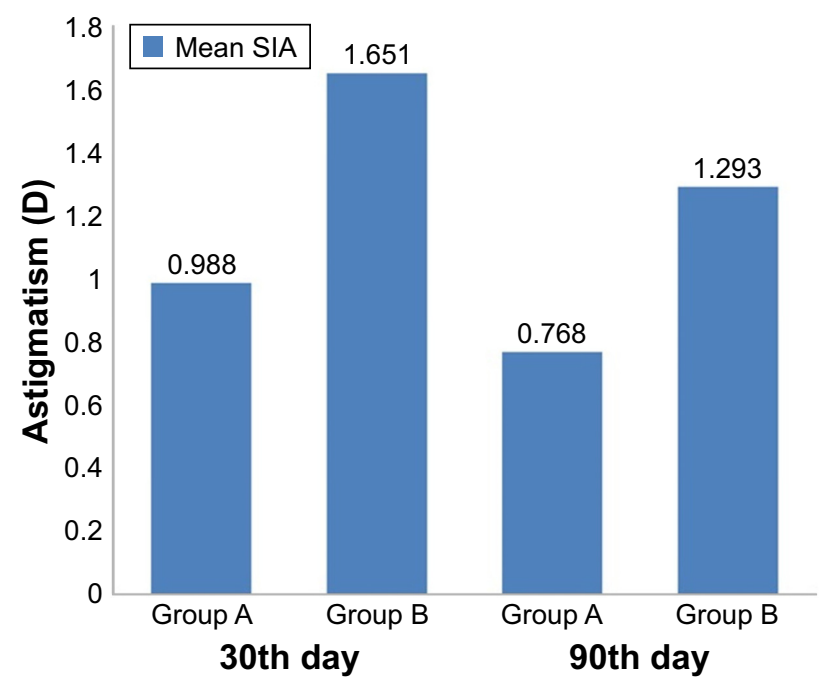

Figure 3 SIA in group A and group B on 30th and 90th day. Group A, temporal approach; Group B, superior approach.

Abbreviation: SIA, surgically induced astigmatism. on-axis group. Finally they concluded that the clear corneal temporal incision induced less SIA than clear corneal on the axis incision.

Marek et a $1^{10}$ compared SIA of temporal versus superior $2.8 \mathrm{~mm}$ clear corneal incisions. The mean SIA in the temporal group was $0.63 \pm 0.28 \mathrm{D}$ and it was $1.00 \pm 0.54 \mathrm{D}$ in the superior group, and the differences were statistically significant $(p<0.05)$. They also concluded that clear corneal temporal approach of $2.8 \mathrm{~mm}$ was better than the superior clear corneal incision of the same size.

Likewise, Wei et $\mathrm{al}^{11}$ studied the influence of corneal wound size on surgically induced corneal astigmatism after phacoemulsification with unsutured temporal clear corneal incisions. They compared 2.5 and $3.5 \mathrm{~mm}$ wound sizes. SIA was calculated by vector analysis using the Alpin's method. They found that mean SIA in the $2.5 \mathrm{~mm}$ incision group was $0.84 \pm 0.53 \mathrm{D}$, whereas in the $3.5 \mathrm{~mm}$ group it was $1.19 \pm 0.81 \mathrm{D}$, and so they concluded that the mean SIA in the $3.5 \mathrm{~mm}$ group was larger than in the $2.5 \mathrm{~mm}$ group.

Barequet et $\mathrm{al}^{12}$ demonstrated a mean SIA of $1.17 \mathrm{D}$ at 6 weeks and $1.04 \mathrm{D}$ at 12 months by vector analysis. The side of the incision significantly affected SIA. At 6 weeks, temporal incisions induced a mean SIA of $0.74 \mathrm{D}$, and nasal incisions of $1.65 \mathrm{D}$, which reduced to $0.71 \mathrm{D}$ for temporal incisions and $1.41 \mathrm{D}$ for nasal incisions at 12 months. They finally concluded that temporal incisions induced significantly less astigmatism than nasal incisions, which is similar to our conclusion.

Al Mahmood et al ${ }^{13}$ discussed that clear corneal incisions are very appealing, but not devoid of complications. The various disadvantages were irregular astigmatism, poor wound healing, and loss of endothelial cells.

From this discussion, we can say that temporal clear corneal approach is highly feasible and induces lesser SIA compared to superior corneal incision. Improvement of visual acuity is the ultimate goal of cataract surgery, and we observed better improvement with temporal approach than superior approach in phacoemulsification technique.

\section{Conclusion}

Our study demonstrated the effect on corneal astigmatism of two commonly used self-sealing incisions in phacoemulsification with foldable IOL. In spite of various modifications in the cataract surgery, phacoemulsification remains the fastest and best surgical procedure. A temporal approach is more accessible than superior approach as a prominent brow and deep-set sunken eyes obstruct the maneuvering of the probe in the superior approach, which is easier and more 
accessible in temporal approach. A self-sealing corneal incision gives a bloodless surgical field. A well-formed $2.8 \mathrm{~mm}$ biplanar clear corneal incision gives excellent wound stability and healing.

SIA in the temporal group is less than in the superior group and gives a better visual outcome, good optical quality, and great patient satisfaction.

\section{Disclosure}

The authors report no conflicts of interest in this work.

\section{References}

1. Aykut V, Kirgiz A, Gulay B, Celik U. Comparison of pre-incision and single-stepped clear corneal incision in phacoemulsification cataract surgery. Eur Rev Med Pharmacol Sci. 2014;18:1698-1703.

2. Lin $\mathrm{H}, \mathrm{He} \mathrm{M}$, Congdon $\mathrm{N}$, et al. Clinical evaluation of three incision size-dependent phacoemulsification systems. Am J Ophthalmol. 2012;153(5):831-839.

3. Pakravan M, Nikkhah H, Yazdani S, Shahabi C, Sedigh Rahimabadi M. Astigmatic outcomes of temporal versus nasal corneal phacoemulsification. J Ophthalmic Vis Res. 2009;4(2):79-83.

4. Moon SC, Mohamed T, Howard Fine I. Comparison of surgically induced astigmatisms after clear corneal incisions of different sizes. Korean $J$ Ophthalmol. 2007;21(1):1-5.
5. He Y, Zhu S, Chen M, Li D. Clinical study: comparision of Keratometric corneal astigmatism power after phacoemulsification: clear temporal corneal incision versus superior scleral tunnel incison. $J$ Ophthalmol. 2009;2(10):6-21.

6. Kaiser PK. Prospective evaluation of visual acuity assessment: a comparison of Snellen's versus ETDRS charts in clinical practice. Trans Am Ophthalmol Soc. 2009;107:311-324.

7. Je HY, Kyun HK, Dong HN. Surgically induced astigmatism after $3.0 \mathrm{~mm}$ temporal and nasal clear corneal incisions in bilateral cataract surgery. Indian J Ophthalmol. 2013;61(11):645-648.

8. Giansanti F, Rapizzi E, Virgili G, et al. Clear corneal incision of $2.75 \mathrm{~mm}$ for cataract surgery induces little change of astigmatism in eyes with low preoperative corneal cylinder. Eur J Ophthalmol. 2006; 16:385-393.

9. Borasio E, Mehta JS, Maurino V. Surgically induced astigmatism after phacoemulsification in eyes with mild to moderate corneal astigmatism: temporal versus on-axis clear corneal incisions. J Cataract Refract Surg. 2006;32(4):565-572.

10. Marek R, Kluś A, Pawlik R. Comparison of surgically induced astigmatism of temporal versus superior clear corneal incisions. KlinOczna. 2006;108(10-12):392-396.

11. Wei YH, Chen WL, Su PY, Shen EP, Hu FR. The influence of corneal wound size on surgically induced corneal astigmatism after phacoemulsification. J Formosan Med Assoc. 2012;111:284-289.

12. Barequet IS, Yu E, Vitale S, et al. Astigmatism outcomes of horizontal temporal versus nasal clear corneal incision cataract surgery. $J$ Cataract Refract Surg. 2004;30:418-423.

13. Al Mahmood AM, Al-Swailem SA, Behrens A. Clear corneal incision in cataract surgery. Middle East Afr J Ophthalmol. 2014;21(1):25-31.
Clinical Ophthalmology

\section{Publish your work in this journal}

Clinical Ophthalmology is an international, peer-reviewed journal covering all subspecialties within ophthalmology. Key topics include: Optometry; Visual science; Pharmacology and drug therapy in eye diseases; Basic Sciences; Primary and Secondary eye care; Patient Safety and Quality of Care Improvements. This journal is indexed on

\section{Dovepress}

PubMed Central and CAS, and is the official journal of The Society of Clinical Ophthalmology (SCO). The manuscript management system is completely online and includes a very quick and fair peer-review system, which is all easy to use. Visit http://www.dovepress.com/ testimonials.php to read real quotes from published authors. 